\title{
Pertumbuhan Bibit Anggur Prabu Bestari Asal Okulasi pada Berbagai Campuran dan Kandungan Air Media Tanam
}

\author{
I GUSTI ALIT GUNADI*) DAN I KETUT SUMIARTHA
}

\author{
Program Studi Agroekoteknologi Fakultas Pertanian Universitas Udayana \\ Jl. PB. Sudirman, Denpasar 80231 Bali \\ ${ }^{*}$ E-mail: gunadiya@gmail.com
}

\begin{abstract}
The Growth and Development of the Prabu Bestari Grape Seedling on Various Compositions and Water Content of Growing Media. The growth and development of the grape seedling influenced by the presence of solar and ground water energy. Prabu Bestari is a originally variety introduced by Balitjestro from Australia after being assembled with the selection process. The need for this variety of agroclimates is in accordance with the North Bali region as a production center. The bud break in grape plant can be affected by condition of plant media during the seedling procession. Shoot failure in grapes can be caused by the condition of the planting medium in the nursery process. This study aims to determine the growth of grape seedlings that are treated with the use of planting media (soil, soil, chaff, soil + cocopeat, and soil compost) 1: 1 (v/v) mixture ratio. The planting media treatment will be combined with different water content $(100 \%, 75 \%$, and $50 \%$ of the field capacity conditions). The study was conducted in a green house at the Experimental Station of Faculty of Agriculture Udayana University from May to August 2018. The research used factorial method $(4 \times 3)$ which was designed randomly in groups with three replications. The results showed no interaction on all parameters observed. Increasing length of tendrils $(148.16 \mathrm{~cm})$ and number of leaves $(26.58$ strands) looks better with increasing groundwater content up to $100 \%$ of field capacity, whereas the resistant mixture + compost gave the highest increase in tendril length $(131.91 \mathrm{~cm})$ and the number of leaves (26.56 pieces). The highest chlorophyll content of the leaves reached 28.68 SPAD unit in a mixture of soil + compost treatment and the lowest was in land use + cocopeat with 18.99 SPAD unit. While the highest leaf chlorophyll content due to water content treatment was shown in $100 \%$ of field capacity treatment of 27.84 SPAD unit.
\end{abstract}

Keywords: prabu bestari, media, composition, water content

\section{PENDAHULUAN}

Varietas anggur Prabu Bestari merupakan anggur introduksi dari Australia yang telah dirakit Balai Penelitian Tanaman
Jeruk dan Buah Subtropika melalui seleksi.

Ukuran buah besar dan berwarna merah menarik, daya hasil tinggi (10-30 kg/pohon), serta kandungan vitamin C mencapai 23,23 
I GUSTI ALIT GUNADI DAN I KETUT SUMIARTHA. Pertumbuhan Bibit Anggur Prabu Bestari...

mg/100 g yang merupakan keunggulan spesifik varietas anggur Prabu Bestari. Jenis anggur ini mampu beradaptasi pada ketinggian 25-300 m dpl. (Imam Priyadi, 2011).

Pemeliharaan bibit dilakukan di tempat terbuka, diberi naungan atap paranet/rumbia agar cahaya yang masuk sekitar $60 \%$. Pemeliharaan dilakukan hingga anakan mencapai kondisi siap tanam dengan tinggi ata-rata $30 \mathrm{~cm}$.

Faktor yang mempengaruhi pertumbuhan tanaman terdiri dari faktor internal dan faktor eksternal. Faktor internal merupakan faktor yang terdapat pada benih, bibit atau tanaman itu sendiri. Faktor eksternal merupakan faktor yang terdapat di luar benih, bibit atau tanaman, salah satu yang mempengaruhi pertumbuhan yaitu media tanam. Media tanam yang baik adalah media yang mampu menyediakan air dan unsur hara dalam jumlah cukup bagi pertumbuhan tanaman. Hal ini dapat ditentukan pada tanah dengan tata udara dan air yang baik, mempunyai agregat yang mantap, kemampuan menahan air yang baik dan ruang untuk perakaran yang cukup (Gardner at al., 1991). Penggunaan media tanam yang sifatnya menyimpan air lebih banyak akan mengakibatkan akar dan batang bagian bawah sirih merah dapat membusuk dan jenis media tanam yang memiliki sifat kemampuan menahan air rendah akan mengakibatkan media tanam mudah kering dan tanaman akan cepat mati. Media tanam yang baik harus memiliki persyaratanpersyaratan sebagai tempat berpijak tanaman, memiliki kemampuan mengikat air dan menyuplai unsur hara yang dibutuhkan tanaman, mampu mengontrol kelebihan air (drainase) serta memiliki sirkulasi dan ketersediaan udara (aerasi) yang baik, dapat mempertahankan kelembaban di sekitar akar tanaman dan tidak mudah lapuk atau rapuh. Kokopit/cocopeat memiliki kemampuan memegang air yang baik, sehingga dalam bidang pertanian sering dimanfaatkan sebagai pencampur media tanam atau bahkan sebagai media tanam pengganti tanah. Berdasarkan beberapa kajian, diketahui kandungan nutrien dalam kokopit rendah, sehingga perlu ditambahkan komponen lain sebagai media tanam pengganti tanah. Penambahan kompos atau pupuk organik lain serta sekam akan menjadi alternatif campuran media tanam yang baik. Kokopit secara alami dikatakan masih mengandung fungi yaitu Trichoderma sp. yang bersimbiosis dengan kokopit melawan fungi patogen Phytium sp. (Anissa, 2009).

Pupuk kandang sapi memiliki keunggulan kandungan serat yang tinggi 
seperti selulosa, menyediakan unsur hara makro dan mikro bagi tanaman, serta mampu memperbaiki daya pegang air tanah (Hartatik dan Widowati, 2010).

Sekam juga media tanam yang bagus. Hasil penelitian yang dilakukan oleh Syafril (1999), penggunaan sekam sebagai media tanam pada pertumbuhan stek cabang tanaman lada memberikan hasil yang lebih baik dibandingkan dengan penggunaan abu sekam sebagai media tanam. Kokopit juga bermanfaat sebagai media tanam selain banyak tersedia juga dapat menyimpan air seperti halnya tanah. Memiliki porositas yang cukup tinggi namun bisa diatur kepadatannya hingga mencapai tingkat porositas dengan mengatur rasio pemberian air (Imron, 2013). Oleh karena itu penulis ingin meneliti sejauh mana pengaruh dari pemberian berbagai macam media tanam tehadap pertumbuhan bibit anggur asal okulasi (Vitis vinifera L.).

Beberapa jenis bahan organik yang dapat dijadikan sebagai media tanam diantaranya arang sekam, cacahan pakis, sebuk sabut kelapa dan humus daun bambu. Arang sekam bersifat porous dan tidak dapat menggumpal/memadat sehingga akar tanaman dapat tumbuh dengan baik dan sempurna. Penelitian ini diarahkan pada penggunaan berbagai campuran media dan kandungan air media tanam. Jenis media tanam yang sifatnya porus dan mampu menyimpan air lebih lama pada bibit anggur, akan mempengaruhi pertumbuhan bibit anggur.

\section{METODE PENELITIAN}

\section{Tempat dan Waktu Penelitian}

Penelitian ini dilaksanakan pada rumah paranet di Kebun Percobaan Fakultas Pertanian Kecamatan Denpasar Selatan Kota Denpasar pada ketinggian $25 \mathrm{~m}$ dpl. Penanaman dimulai tanggal 19 Mei dan penelitian lapangan berakhir sampai akhir Agustus 2018.

\section{Bahan dan Alat}

Bahan bangunan paranet shading dalam rumah plastik, bibit anggur Prabu Bestari Merah (BS-89), pot plastik, media tanam (tanah, arang sekam, kokopit, dan kompos), dan insektisida seperlunya. Sedangkan alat yang digunakan antara lain Spad metter, alat tulis, penggaris, hand counter, dan pengukur diameter batang.

\section{Rancangan Penelitian}

Penelitian ini dilaksanakan dengan menggunakan rancanngan lapangan Acak Kelompok dengan alokasi perlakuan secara faktorial $(4 \times 3)$. Perlakuan yang dicoba pada penelitian ini terdiri atas dua faktor yaitu: 
I GUSTI ALIT GUNADI DAN I KETUT SUMIARTHA. Pertumbuhan Bibit Anggur Prabu Bestari...

Jenis media tanam terdiri atas 4 taraf dengan rasio campuran berdasarkan volume (1:1): T (media tanah), TAs (media campuran tanah dan arang sekam), TCo (media campuran tanah dan cocopeat), TKo (media campuran tanah dan kompos), kandungan air media tanam terdiri atas 3 taraf: $100 \%, 75 \%$, dan $50 \%$ kapasitas lapang (FC), yang dilakukan dengan 3 kali ulangan. Sehingga diperoleh 36 faktor kombinasi yaitu: T_100, T_75, T_50, TAs_100, TAs_75, TAs_50, TAs_100, TAs_75, TAs_50, TKo_100, TKo_75, dan TKo_50. Setiap kombinasi terdiri dari 1 tanaman, masingmasing kombinasi diulang tiga (3) kali sehingga 36 stek nilam. Bentuk umum dari model linier rancangan acak kelompok (RAK) adalah sebagai berikut:

$$
\text { Yij }=\mu+\mathrm{Kj}+\alpha \mathrm{i}+\varepsilon \mathrm{ij}
$$

\section{Keterangan:}

$\mathrm{i} \quad=1,2,3, ., \mathrm{p}$ (Jumlah perlakuan) dan

$\mathrm{j} \quad=1,2,3, . ., 1$ (Jumlah kelompok).

Yij $=$ nilai pengamatan pada satuan percobaan $\mu=$ nilai tengah umum

$\mathrm{Kj}$ = pengaruh perlakuan kelompok ke- $\mathrm{j}$

$\mathrm{Ai}=$ pengaruh perlakuan taraf $\mathrm{ke}-\mathrm{i} \varepsilon \mathrm{ij}=$ galat percobaan pada satuan percobaan kelompok ke - j perlakuan taraf ke-i. Untuk Uji Lanjut menggunakan Uji Beda Nyata Terkecil (BNT) taraf $5 \%$

\section{Pelaksanaan Percobaan}

Pembuatan paranet shading dalam rumah plastik dan media tanam

Paranet shading dalam rumah plastik dibuat dengan ukuran $\pm 25 \mathrm{~m}^{2}$ menggunakan bahan tiang beton pada ketinggian 2,5 $\mathrm{m}$ dari permukaan pot dengan atap plastik UV dilengkapi dengan plafon paranet rangkap agar bibit terhindar dari radiasi matahari langsung.

Media tanam yang terdiri atas empat jenis (tanah, arang sekam, cocopeat, dan bahan organik yang berasal dari kompos
SIMANTRI). Selain media tanah masingmasing bahan dicampur dengan tanah dengan perbandingan 1:1 (v/v) dan selanjutnya dimasukkan ke dalam pot plastik kapasitas 5 kg media kering udara.

\section{Penyiapan media tanam dan bibit}

Semua jenis media tanam dikering anginkan sebelum dilakukan pencampuran. Selanjutnya dalam kondisi kering angin, media tanam dicampur sesuai rasio yang telah ditentukan $(1: 1)$. 
Bibit yang akan digunakan berasal dari bibit okulasi dengan ukuran yang relatif sama (data awal bibit terkait dengan variabel yang diamati dicatat dengan baik). Media tanah yang berasal dari okulasi bibit diupayakan seminimal mungkin, agar tidak mengganggu rasio campuran media tanam sebagai perlakuan.

\section{Pengairan/penyiraman}

Masing-masing campuran media diairi sampai mencapai $100 \%$ kapasitas lapang. Volume air yang terkandung pada saat kapasitas lapang dipakai sebagai penentuan perlakuan $75 \%$ dan $50 \%$. Kondisi kandungan air pada setiap perlakuan diupayakan setiap penyiraman.

\section{Pengendalian OPT}

Pengendalian Organisme Pengganggu Tanaman (OPT) dilakukan dengan prinsip Pengendalian Hama Terpadu (PHT) dan mengutamakan pengendalian secara fisik. Pengendalian tanaman pengganggu (gulma) dilakukan secara fisik (dicabut), sedangkan pengendalian hama penyakit dilakukan dengan menggunakan pestisida organik dan pestisida kimiawi yang diaplikasikan sesuai dengan tingkat serangan OPT. Sementara sampai saat laporan ini dibuat, hanya terlihat gejala serangan jamur daun.

\section{Pengumpulan Data}

Data yang diamati meliputi pertumbuhan tanaman yaitu, jumlah daun pada sulur $(\mathrm{cm})$, diameter batang, diameter sulur $(\mathrm{cm})$, panjang sulur $(\mathrm{cm})$, kholofil daun (Spad-502), pertambahan panjang sulur $(\mathrm{cm})$, pertambahan jumlah daun (helai), dan pertambahan diameter batang $(\mathrm{cm})$. Pengamatan dilakukan

\section{HASIL DAN PEMBAHASAN}

\section{Hasil}

Pengaruh interaksi antara penggunaan jenis dan kandungan air media tanam terhadap semua parameter yang diamati tidak memberikan pengaruh yang nyata pada taraf uji BNT 5\% (Tabel 1). Mengingat tidak terjadi interaksi yang nyata, maka hasil dam pembahasan akan dirahkan pada pengaruh masing-masing faktor yakni jenis madia dan kandungan air media. 
I GUSTI ALIT GUNADI DAN I KETUT SUMIARTHA. Pertumbuhan Bibit Anggur Prabu Bestari...

Tabel 1. Pengaruh Media Tanam dan Kandungan Air terhadap Parameter Pertumbuhan

\begin{tabular}{|c|c|c|c|c|c|c|c|c|c|c|c|}
\hline \multirow[b]{2}{*}{ SK } & \multirow[b]{2}{*}{$\mathrm{db}$} & \multicolumn{8}{|c|}{ F- hitung parameter pengamatan } & \multicolumn{2}{|c|}{$\mathrm{F}$ - tabel } \\
\hline & & $\begin{array}{l}\sum \text { daun } \\
\text { sulur }\end{array}$ & $\begin{array}{c}\varnothing \\
\text { batang }\end{array}$ & $\begin{array}{c}\varnothing \\
\text { sulur }\end{array}$ & $\begin{array}{l}\text { Panjang } \\
\text { sulur }\end{array}$ & $\begin{array}{c}\text { SPAD- } \\
502 \\
\text { daun }\end{array}$ & $\begin{array}{c}\partial \\
\text { panjang } \\
\text { sulur }\end{array}$ & $\begin{array}{c}\partial \\
\text { jumlah } \\
\text { daun }\end{array}$ & $\begin{array}{c}\partial \varnothing \\
\text { batang }\end{array}$ & $5 \%$ & $1 \%$ \\
\hline Ulangan & 2 & 0,61 & 2,40 & 0,36 & 3,34 & 0,77 & 2,94 & 0,62 & 0,45 & 3,44 & 5,72 \\
\hline Perlakuan & 11 & $5,11 * *$ & 0,59 & 1,20 & $10,09 * *$ & $4,73 * *$ & $10,25 * *$ & $4,98 * *$ & 0,51 & 2,30 & 3,26 \\
\hline Media & 3 & $5,85^{* *}$ & 0,90 & 1,37 & $9,07 * *$ & $11,78 * *$ & $8,95 * *$ & $5,17 * *$ & 0,83 & 3,05 & 4,82 \\
\hline Air & 2 & $16,45 * *$ & 0,43 & 0,92 & $37,39 * *$ & $5,78 * *$ & $38,00 * *$ & $15,73 * *$ & 1,12 & 3,44 & 5,72 \\
\hline MediaxAir & 6 & 0,97 & 0,48 & 1,21 & 1,51 & 0,85 & 1,66 & 1,30 & 0,14 & 2,55 & 3,76 \\
\hline Acak & 22 & - & - & - & - & - & - & - & - & - & - \\
\hline Total & 35 & - & - & - & - & - & - & - & - & - & - \\
\hline
\end{tabular}

Pengaruh perlakuan jenis media tanam menunjukkan perbedaan yang tidak nyata terhadap parameter diameter batang, diameter sulur, dan pertambahan diameter batang selama periode penelitian ( \pm 3 bulan). Berdasarkan hasil pengamatan, penggunaan media tanah+kompos menunukkan nilai yang cenderung lebih baik yakni secara bertuturutturut $\varnothing=0,78 \mathrm{~cm}$ untuk diameter batang, $\varnothing=0,51 \mathrm{~cm}$ untuk diameter sulur, dan $\partial \varnothing=0,13 \mathrm{~cm}$ terhadap pertambahan diameter batang terhitung sejak awal penelitian sampat akhir penelitian (Tabel 2). Sedangkan kecenderungan nilai parameter tersebut nampak semakin membaik dengan meningkatnya kandungan air tanah hingga mencapai $100 \%$ kapasitas lapang. Pengaruh perlakuan jenis dan kandungan air media tanam menunjukkan pengaruh yang nyata hingga sangat nyata seperti terlihat pada Tabel 1. Sedangkan Tabel 3 memberikan petunjuk bahwasanya perlakuan jenis media tanah+kompos (Tko) memberikan kualitas hasil yang terbaik yakni dengan nilai tertinggi pada jumlah daun pada sulur $(36,6$ helai), panjang sulur $(143,7 \mathrm{~cm})$, kandungan khlorofil pada daun (28,68 Spad-502), pertambahan (D) panjang sulur selama penelitia berlangsung $(131,91 \mathrm{~cm})$, dan pertambahan (2) jumlah daun selama penelitian yakni 26,56 helai. 
Tabel 2. Pengaruh Perlakuan Jenis Dan Kandungan Air Media Tanam terhadap Diameter Batang, Diameter Sulur, dan Pertambahan Diameter Batang

\begin{tabular}{llll}
\hline \multirow{2}{*}{ Perlakuan } & P a r a m e t e r & P e n g a m a t a n & \\
\cline { 2 - 4 } & $\varnothing$ batang $(\mathrm{cm})$ & $\varnothing$ sulur $(\mathrm{cm})$ & $\partial \varnothing$ batang $(\mathrm{cm})$ \\
\hline T & 0,74 & 0,51 & 0,10 \\
\hline Tas & 0,69 & 0,45 & 0,13 \\
\hline Tco & 0,75 & 0,48 & 0,07 \\
\hline Tko & 0,73 & 0,51 & 0,13 \\
\hline BNT 5\% & $\mathrm{ns}$ & $\mathrm{ns}$ & $\mathrm{ns}$ \\
\hline $100 \%$ FC & 0,76 & 0,51 & 0,12 \\
\hline $75 \%$ FC & 0,76 & 0,47 & 0,12 \\
\hline 50\% FC & 0,70 & 0,49 & 0.08 \\
\hline BNT 5\% & $\mathrm{ns}$ & $\mathrm{ns}$ & $\mathrm{ns}$ \\
\hline
\end{tabular}

Perlakuan kandungan air pada media terhadap parameter : jumlah daun pada sulur tanam memberikan pengaruh yang nyata mencapai 36,5 helai, panjang sulur hingga yakni pengaruhnya semakin membaik 159,7 cm, kandungan khlorofil daun sebesar dengan semakin meningkatnya kandungan 27,84 SPAD, pertambahan panjang sulur air hingga mencapai kondisi 100\% kapasitas sebesar 148,16 cm, dan pertambahan jumlah lapang (FC). Perlakuan 100\% FC daun mencapai 26,53 helai. memberikan efek yang paling baik

Tabel 3. Pengaruh Perlakuan Jenis dan Kandungan Air Media Tanam Terhadap Jumlah Daun Sulur, Panjang Sulur, Kandungan Khlorofil Daun, Pertambahan Panjang Sulur, Pertambahan Jumlah Daun Sulur

\begin{tabular}{llllll}
\hline \multirow{2}{*}{ Perlakuan } & \multicolumn{5}{c}{ P a r a m e t e r P e n g a m a t a n } \\
\cline { 2 - 7 } & $\begin{array}{l}\Sigma \text { daun } \\
\text { (helai) }\end{array}$ & $\begin{array}{l}\text { sulur } \\
\text { Tanjang } \\
\text { sulur (cm) }\end{array}$ & $\begin{array}{l}\text { Khlorofil } \\
\text { daun (SPAD) }\end{array}$ & $\begin{array}{l}\partial \text { panjang } \\
\text { sulur (cm) }\end{array}$ & $\begin{array}{l}\partial \text { jumlah } \\
\text { (helai) }\end{array}$ \\
\hline Tas & $29,2 \mathrm{~b}$ & $118,9 \mathrm{~b}$ & $28,56 \mathrm{a}$ & $107,33 \mathrm{~b}$ & $19,00 \mathrm{~b}$ \\
\hline Tco & $25,4 \mathrm{c}$ & $95,6 \mathrm{c}$ & $29,69 \mathrm{a}$ & $84,14 \mathrm{c}$ & $16,00 \mathrm{bc}$ \\
\hline Tko & $23,8 \mathrm{c}$ & $78,3 \mathrm{~d}$ & $18,99 \mathrm{~b}$ & $67,91 \mathrm{~d}$ & $14,33 \mathrm{c}$ \\
\hline BNT5\% & $\mathbf{3 , 3 2}$ & $143,7 \mathrm{a}$ & $28,68 \mathrm{a}$ & $131,91 \mathrm{a}$ & $26,56 \mathrm{a}$ \\
\hline $100 \%$ FC & $36,5 \mathrm{a}$ & $\mathbf{1 3 , 3 5}$ & $\mathbf{1 , 6 0}$ & $\mathbf{1 3 , 1 9}$ & $\mathbf{3 , 3 7}$ \\
\hline 75\% FC & $29,7 \mathrm{~b}$ & $159,7 \mathrm{a}$ & $27,84 \mathrm{a}$ & $148,16 \mathrm{a}$ & $26,58 \mathrm{a}$ \\
\hline $50 \%$ FC & $20,1 \mathrm{c}$ & $108,0 \mathrm{~b}$ & $27,80 \mathrm{a}$ & $96,71 \mathrm{~b}$ & $20,00 \mathrm{~b}$ \\
\hline BNT5\% & $\mathbf{2 , 8 8}$ & $59,7 \mathrm{c}$ & $24,39 \mathrm{~b}$ & $48,61 \mathrm{c}$ & $10,33 \mathrm{c}$ \\
\hline KN & $\mathbf{1 1 , 5 6}$ & $\mathbf{1 , 3 8}$ & $\mathbf{1 1 , 4 2}$ & $\mathbf{2 , 9 3}$ \\
\hline
\end{tabular}

Keterangan: angka-angka yang diikuti oleh huruf yang sama, pada kolom yang sama menunjukkan tidak berbeda nyata pada taraf uji BNT 5\% 
I GUSTI ALIT GUNADI DAN I KETUT SUMIARTHA. Pertumbuhan Bibit Anggur Prabu Bestari...

Efek masing-masing perlakuan dengan perlakuan kandungan air terhadap jumlah daun pada sulur menunjukkan pengaruh yang signifikan menunjukkan hasil yang signifikan. Jumlah terhadap jumlah daun yang terbentuk pada daun yang tertinggi terlihat pada perlakuan sulur. Nampak semakin tinggi kandungan air Tko (campuran tanah dan kompos) 36,6 helai media tanam sampai mencapai $100 \%$ FC, dan yang jumlah daun terkecil terlihat pada akan meningkatkan terbentuknya daun perlakuan Tco (campuran tanah dan (Tabel 3 dan Gambar 1 dan 2). cocopeat) 23,8 helai. Demikian pula halnya
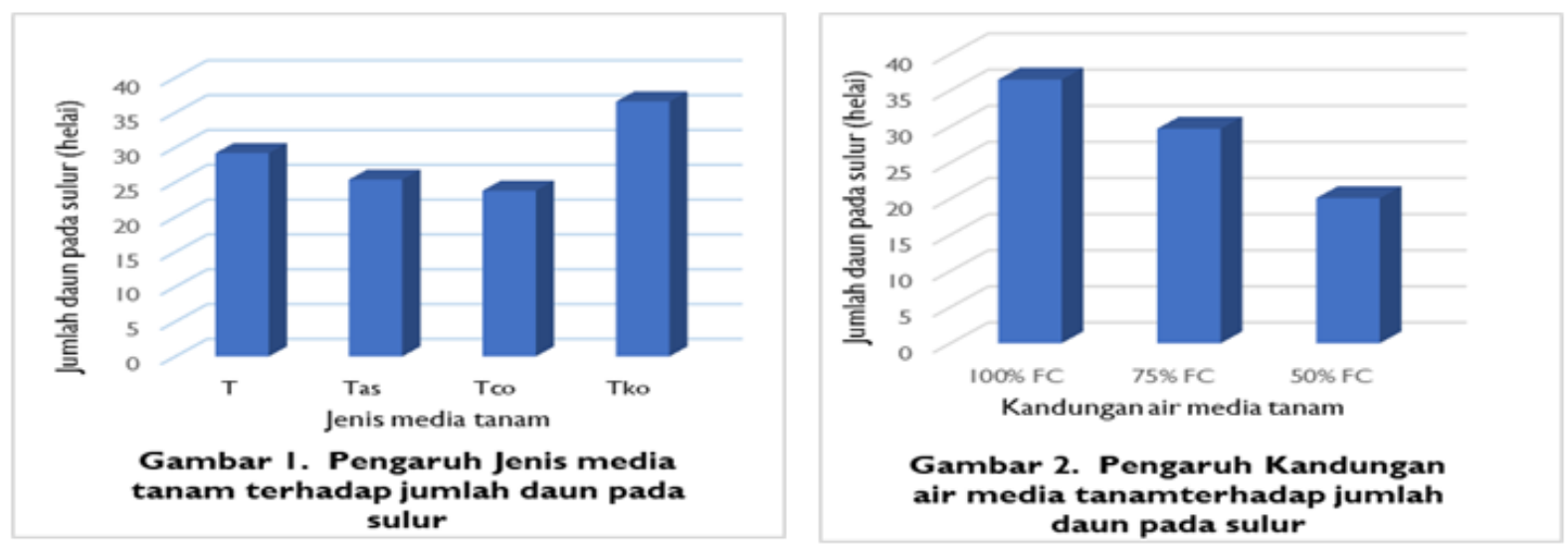

Pengaruh perlakuan jenis media tanam dan kandungan air media tanam memberikan pengaruh yang signifikan terhadap panjang sulur. Sulur terpanjang ditunjukkan oleh perlakuan Tko $(143,7 \mathrm{~cm})$ dan terpendek terlihat pada perlakuan Tco $(78,3 \mathrm{~cm})$.
Sedangkan sulur terpanjang efek perlakuan kandungan air media tanam terlihat pada perlakuan $100 \% \quad \mathrm{FC} \quad(159,7 \quad \mathrm{~cm})$ dan terpendek pada perlakuan 50\% FC $(59,7 \mathrm{~cm})$ (Tabel 3 dan Gambar 3 dan 4). 



Pengaruh perlakuan jenis media tanam

SPAD). Sedangkan kandungan khlorofil dan kandungan air media tanam memberikan tetinggi efek perlakuan kandungan air media pengaruh yang signifikan terhadap tanam terlihat pada perlakuan 100\% FC kandungan khlorofil pada daun. Kandungan khlorofil tertinggi ditunjukkan oleh perlakuan Tko (28,68 SPAD) dan 5 dan 6).

terendah terlihat pada perlakuan Tco $(18,99$
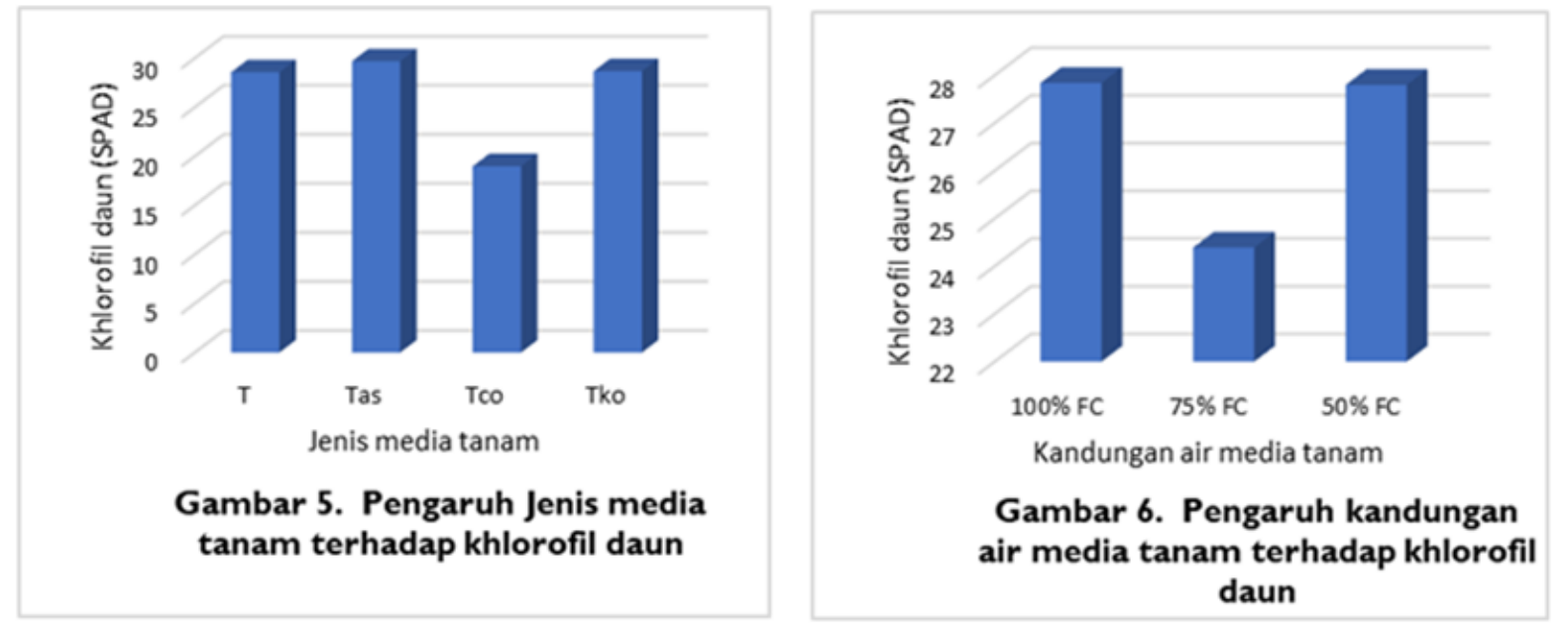

Pengaruh perlkuan jenis media tanam panjang sulur terbesar ditunjukkan oleh dan kandungan air media tanam memberikan perlakuan Tko $(131,91 \mathrm{~cm})$ dan terendah pengaruh yang signifikan terhadap terlihat pada perlakuan Tco $(67,91 \mathrm{~cm})$. pertambahan panjang sulur $(\partial)$. Pertambahan Sedangkan kandungan khlorofil tetinggi efek 
I GUSTI ALIT GUNADI DAN I KETUT SUMIARTHA. Pertumbuhan Bibit Anggur Prabu Bestari...

perlakuan kandungan air media tanam terlihat pada perlakuan $100 \%$ FC $(148,16$

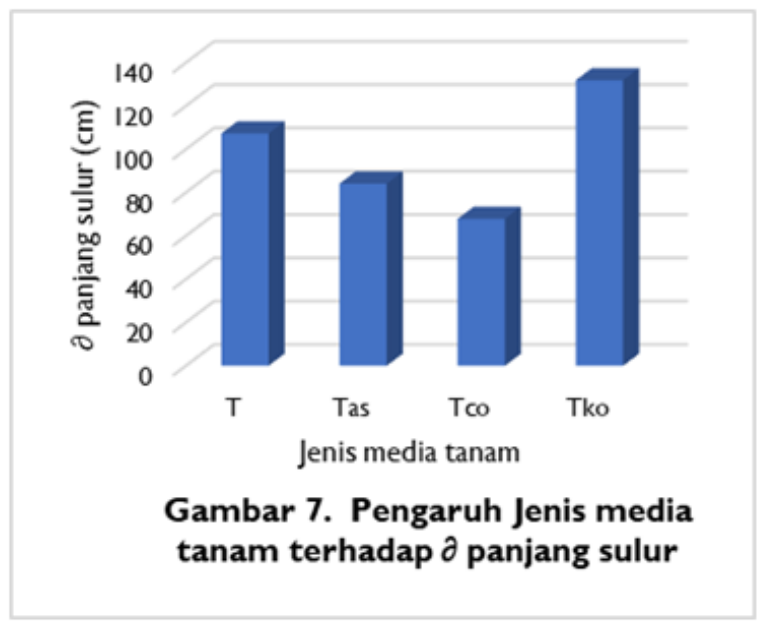

Pengaruh peralkuan jenis media tanam dan kandungan air media tanam memberikan pengaruh yang signifikan terhadap pertambahan jumlah daun $(\partial)$. Pertambahan jumlah daun terbesar ditunjukkan oleh perlakuan Tko (26,56 helai) dan terendah

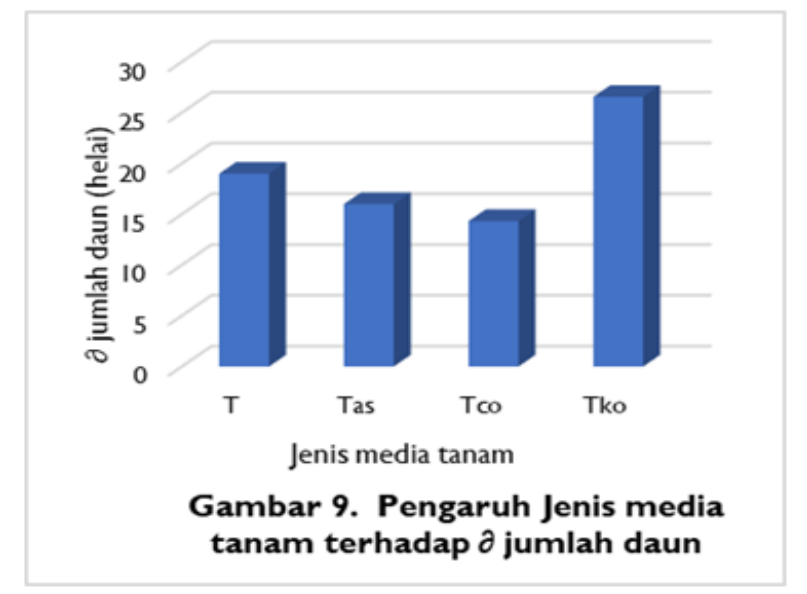

$\mathrm{cm})$ dan terendah pada perlakuan 50\% FC $(48,61 \mathrm{~cm})$ (Tabel 3 dan Gambar 7 dan 8).

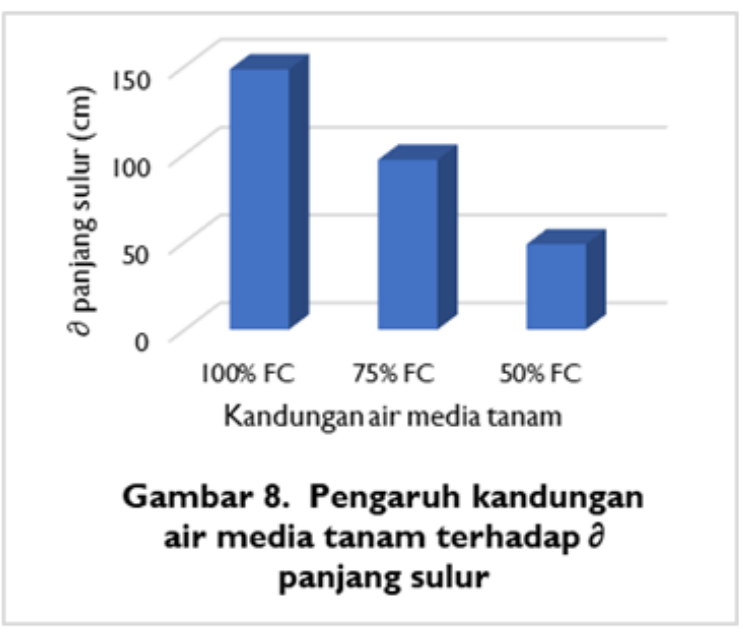

terlihat pada perlakuan Tco (14,33 helai). Sedangkan kandungan khlorofil tetinggi efek perlakuan kandungan air media tanam terlihat pada perlakuan $100 \%$ FC $(26,58$ helai) dan terendah pada perlakuan $50 \%$ FC (10,33 helai) (Tabel 3 dan Gambar 9 dan 10).

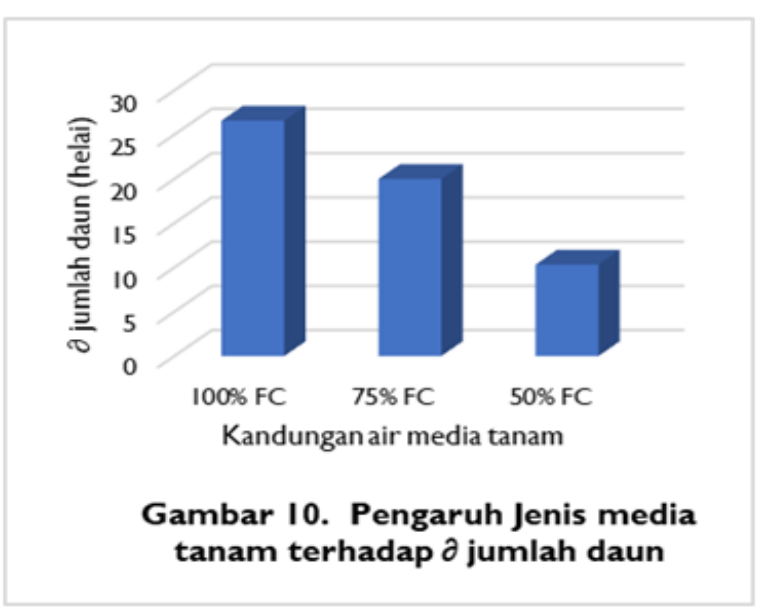




\section{Pembahasan}

Pertumbuhan dan perkembangan tanaman anggur di lapangan produksi berkaitan erat dengan kualitas bibit yang akan digunakan. Proses pembibitan yang baik ditandai dengan didahului oleh proses pembentukan dan pertumbuhan akar. Apabila proses pembibtan didahului oleh pembentukan tunas, kegagalan sering akan mengikuti. Gagal tunas (bud break) dalam proses pembuatan bibit diakibatkan dari berkurangya cadangan energi dalam bentuk fotosintat yang tersimpan dalam stek, sementara akar belum sempat tumbuh. Kondisi ini berdampak terhadap ketidak seimbangan antara cadangan energi untuk memacu perkembangan tunas yang terbentuk.

Proses pembentukan akar pada pembibitan anggur, nampaknya memegang peranan penting. Memperbaiki struktur media tanam dapat membantu proses respirasi akar karena ketersediaan oksigen dalam tanah. Proporsional keberadaan poripori mikro dan makro dalam media tanam dapat mengkondisikan media tanam yang optimal untuk pertumbuhan akar.

Hasil penelitian menunjukkan bahwa penggunaan media tanam dari campuran tanah dengan kompos (Tko) yang seimbang (rasio campuran 1:1 berdasarkan volume), memberikan hasil yang terbaik terhadap beberapa parameter yang diamati seperti jumlah daun, panjang sulur, dan khlorifil yang terbentuk serta pertambahan Panjang sulur dan pertmbahan jumlah daun yang terbentuk hingga akhir pengamatan (3 bulan setelah perlakuan). Kompos dengan bahan baku kotoran sapi mengandung kadar serat yang tinggi seperti selulosa, menyediakan unsur hara makro dan mikro bagi tanaman, serta memperbaiki daya serap air pada tanah (Nurhayati Halim, dkk. 1996). Pupuk organik merupakan bahan yang penting dalam menciptakan kesuburan tanah baik secara fisik, kimia dan biologi tanah (Sutarta, 2013 dalam Vika Nurhasanah, dkk. 2016). Secara general.

Hasil penelitian menunjukkan penggunaan media tanam yang terbaik adalah tanah dicampur kompos dan selanjutnya secara berturut-turut diikuti oleh media tanah, media campuran tanah dengan arang sekam, dan terakhir adalah media campuran tanah dengan cocopeat. Media tanah (top soil) pada dasarnya sudah mengandung unsur hara yang tersedia bagi tanaman. Sedangkan arang sekam lebih banyak berfungsi secara fisik untuk memperbaiki struktur media tanam. Menurut Wuryan, 2008 (dalam Helfi Gustia, 2013) disebutkan bahwa arang sekam berperan untuk perbaikan aerasi dan 
I GUSTI ALIT GUNADI DAN I KETUT SUMIARTHA. Pertumbuhan Bibit Anggur Prabu Bestari...

drainase, hal ini disebabkan sekam bakar lebih porous karena memiliki pori-pori makro dan mikro yang hampir seimbang, sehingga sirkulasi udara yang dihasilkan cukup baik serta memiliki daya serap air yang tinggi. Unsur hara yang terkandung pada media tanah saja (100\% tanah dalam per volume pot) nampaknya dapat menyediakan hara yang lebih baik dibandingkan dengan ketersediaan hara pada media $(50 \%$ tanah $+50 \%)$.

Penggunaan media tanam campuran dari $50 \%$ tanah $+50 \%$ cocopeat, menunujukkan semua parameter pertumbuhan yang secara signifikan kurang baik. Hal ini disebabkan karena cocopeat yang digunakan belum diberikan perlakuan sebelumnya. Agustin, dkk. (2017) mengungkapkan, kandungan nutrien yang terkandung dalam kokopit rendah, kadar $\mathrm{pH}$ agak asam, serta banyak mengandung zat tanin. Lebih lanjut dijelaskan bahwasanya zat tanin diketahui sebagai zat yang menghambat pertumbuhan tanaman. Nampaknya pengguaan cocopeat sebagai bahan media tanam, sebaiknya dilakukan pencucian tannin dan lignin agar bias terbebaskan dari lignin dan tanin.

Secara umum telah diketahui bahwa habitat yang baik tanaman anggur, membutuhkan media tanam yang mengandung cukup air dan daerah yang open space (kaki basah dan kepala panas). Walaupun hasil penelitian antar factor tidak menunjukka inetraksi yang signifikan, namun secara parsial tingkat kandungan air pada media tanam menunjukkan perbedaan yang signifikan. Hasil penelitian memberikan indikasi, semakin meningkat kandungan air pada media tanam sampai mencapai tingkat $100 \%$ FC, menunjukkan semua parameter pertumbuhan yang diamati semakin baik. Peningkatan panjang sulur dengan pemberian air $100 \%$ FC memberikan pertambahan panjang sulur mencapai lebih dari dua kali (204,8\%) dibandingakan dengan pemberian air $50 \%$ FC dengan interval penyiraman setiap lima hari sekali. Hal ini sejalan dengan pendapat Sheikholeman and Currie (1977) yang menyatakan bahwa pertumbuhan akar tanaman kedelai semakin baik dengan semakin tinggi kelembaban. Sejalan dengan berkurangnya kandungan air tanah, pertumbuhan tinggi tanaman dan jumlah cabang semua varietas/galur yang diuji cenderung menurun sedangkan umur berbunga nya lebih lambat (Carkum, dkk, 2004). Kapasitas lapang (field capacity) adalah keadaan tanah yang cukup lembab yang menunjukkan jumlah air terbanyak yang dapat ditahan oleh tanah terhadap gaya tarik gravitasi (Wildan, 2012 dalam Cindy 
Angraeny, 2017). Ditegaskan pula bahwa kemampuan tanah menahan air dipengaruhi oleh tekstur tanah dan kandungan bahan organik.

\section{SIMPULAN}

Hasil enelitian menunjukkan bahwa tidak terkadi interaksi antar perlakuan campuran media dengan perbedaan kandungan air media tanam. Namun secara parsial, terjadi pengaruh yang signifikan pada masing-masing perlakuan (jenis media tanam dan kandungan air media tanam) terhadap parameter: jumlah daun sulur, panjang sulur, kandungan khlorofil daun pertambahan panjang sulur, dan pertambahan jumlah daun. Pengaruh perlakuan 1:1 media tanam tanah + kompos (v/v), menunjukkan hasil yang paling baik dari parameter di atas bila dibandingkan dengan perlakuan lainnya. Sedangkan perlakuan kandungan air media tanam yang terbaik adalah dengan penyiraman mencapai $100 \%$ FC setiap lima hari sekali.

Penggunaan cocopeat sebagai
mediatanam ataupun sebagai campuran
media tanam, sebaiknya dilakukan
pembebasan tanin dan lignin yang
terkandung, sehingga tdak menggangu
pertumbuhan tanaman.

\section{DAFTAR PUSTAKA}

Agustin, A.I; T. Yuliana; E.E. Oktafian; V.A. Hadi; dan A.C. Putra. (2017). Pengaruh Cocopeat (serbuk sabut kelapa) Sebagai Media Tanam Krisan di Pot. Karya Ilmiah, Program Studi Manajemen STIE Mahardika Surabaya.

Anissa, 2009. Cocopeat Media Tanam Alternatif Selain Tanah, https: property. kompas. com/ read/2009/04/14/10523297/ cocopeat. media. tanam. alternatif. selain. tanah.

Arif, I. dan Y. Kafiar., 2015. Pemanfaatan cocopeat dan arang sekam padi sebagai media tanam bibit cempaka wasian (Elmerrilia ovalis). Jurnal PROS SEM NAS MASY BIODIV INDON Vol. 1, No. 4, Juli 2015 ISSN: 2407-8050: 805-808.

Astawa ING, R Dwiyani, NNA Mayadewi, IM Sukewijaya, NLM Pradnyawati.2015b. Upaya Perbaikan Kualitas Anggur Bali (Vitis vinifera var. Alphonso lavallee). Disampaikan sebagai makalah poster dalam Seminar Nasional Sains dan Teknologi (Senastek) Universitas Udayana di Kuta Bali pada Tanggal 29-30 Oktober 2015.

Carkum, Kumala Dewi, Parno, dan Sobrizal, 2004. Pengaruh Tingkat Pemberian Air terhadap Komponen Hasil Beberapa Galur Mutan Kacang Tanah (A. hypogaea, L). Risalah Seminar Ilmiah Penelitian dan Pengembangan Aplikasi lsotop dan Radiasi Puslitbang Teknologi Isotop dan Radiasi BATAN, Jakarta.

Cindy Anggraeny, 2017. Kemampuan Kapaliritas air dan Kapasitas Lapang Tanah berdasarkan tekstur dan berbagai jenis tanah. https://caridokumen.com/ download/kemampuan-kapilaritas-airdan-kapasitas-lapang-tanah- 
I GUSTI ALIT GUNADI DAN I KETUT SUMIARTHA. Pertumbuhan Bibit Anggur Prabu Bestari...

berdasarkan-tekstur-dari-berbagai-

jenis-tanah-

_5a461693b7d7bc7b7aedf49d_pdf.FKI

P Universitas Riau, Pekanbaru

Crawford, J.H., 2003. Pupuk Organik. http: //nasih.staff.ugm.ac.id/p/007\%20 p\%20 o.htm. Diaksespada tanggal 12 Juni 2018

Garner, P. F; R. B Preace, and R.L. Mitchell. 1991. Physiology of Crop Plant, terjemahan Fisiologi Tanaman Budidaya. Universitas Indonesia. Jakarta. 428 hal.

Helfi Gustia, 2013. Pengaruh Penambahan Sekam Bakar pada Media Tanam terhadap Pertumbuhan dan Produksi Tanaman Sawi (Brassica juncea L.). EJournal Widya Kesehatan dan Lingkungan Vol. 1 No. 1 Mei-Agustus 2013

http://www.daunku.com/cara-merawatpohon-anggur-tahappemupukan/CaraMenanamAnggur dan Setek Anggur. Download 7 Februari 2018

http://www.grapestutorial.com/2016/02/busu k-akar.html. Penanganan Busuk Akar pada tanaman anggur

Iman Priyadi, 2011. Desiminasi Teknologi Pertanian Anggur. Penyuluh Pertanian Balai Besar pengkajian dan Pengembangan Teknologi Pertanian.

Indrawati, R., D. Indradewa dan S.N.H. Utami, 2012. Pengaruh Komposisi Media dan Kadar Nutrisi Hidroponik Terhadap Pertumbuhan dan Hasil Tomat (Lycopersicon esculentum Mill). UGM, Yogyakarta.

Nugroho, H.P., James, M.R, Manurung, G.F.S, Ery, N., Tukam, J.M., dan Harum, F. 2006. Teknik Pembiitan dan Perbanyakan Vegetatif Tanaman Buah. Penerbit World Agroforestry Centre (ICRAF)\& Winrock International
Nurhayati, H., Yusuf, N., Lubis, A.M., Sutopo, G.N., Rusdi, S., Amin, D., Go, B.H., dan Baily, H.H. 1996. Dasadasar ar Ilmu Tanah. Penerbit Universitas Lampung.

Risnawati, B. (2016). Pengaruh Penambahan Serbuk Serabut Kelapa (Cocopeat) Pada Media Arang Sekam Terhadap Pertumbuhan Tanaman Sawi Hijau (Brassica juncea, L.) Secara Hidroponik. Skripsi Jur. Biologi Fak. Sains dan Teknologi UIN Alaudin Makasar

Sheikholeman, S.W. and H.B Currie. 1977. Effect of Water Stress ON Carbon Assimilation and Distribution in Soybean Plants at Different Stages of Development. Crop Science.

Siswadi, 2015. Pengaruh Macam Media Terhadap Pertumbuhan Dan Hasil Selada (L. sativa L) Hidroponik: Jurnal Agronomika Vol. 09 No. 03, Januari 2015 ISSN: 1693-0142.

Wuryaningsih, S. dan S. Andyantoro. 1998. Pertumbuhan stek melati berbuku satu dan dua pada beberapa macam media. Agri Journal. 5 (1-2): 32-41

Vika Nurhasanah, Wardati, dan Islan (2016). Pengaruh perbandingan medium top soil dengan effluent dan pemberian pupuk NPK pada pada bibit kelapa sawit (Elaeis guineensis Jacq.) Jom Faperta Vol 3 No 1 Februari 2016 